\title{
INTEGRATING FINANCIAL MARKETS IN EAST ASIA
}

\author{
Gordon de Brouwer \\ Australia-Japan Research Centre, APSEM \\ and Division of Economics, RSPAS \\ Australian National University \\ Canberra, ACT 0200 \\ Australia \\ tel: (61-2) 6249-0752 \\ fax: (61-2) 6249-0767 \\ gordon.debrouwer@anu.edu.au
}

This draft: 13 November 2000

\begin{abstract}
Financial markets in east Asia have experienced substantial transformation and turmoil in recent years which has had an effect on the pattern of integration in the region. The paper assesses patterns of common variability in daily changes in interest rates, stock prices and exchange rates in the region using principal component and common factor analysis. It concludes that common variability is greatest in stock prices and exchange rates, that particular patterns of common variability have occurred in both crisis and non-crisis periods at various levels of regional aggregation, and that there is little evidence of a "yen bloc".
\end{abstract}

JEL Classification Numbers: F36, G15, N25 


\title{
INTEGRATING FINANCIAL MARKETS IN EAST ASIA
}

\author{
Gordon de Brouwer
}

\section{Introduction}

It is an understatement to say that financial markets in east Asia have experienced substantial transformation and tumult in recent years. In the past five years, they have gone from the heady halcyon days of "Asian fever" in the mid $1990 \mathrm{~s}^{1}$ to collapse and subsequent partial recovery. In the second half of the 1990s, east Asia's financial markets experienced the best and worst of times and everything in between.

This cannot but have had an effect on the pattern of integration of regional financial markets. This paper attempts to explore and analyse the connections between key financial prices in the region. These financial prices include money market interest rates, stock prices and exchange rates. The region is defined broadly as the ASEAN-5 - Indonesia, Malaysia, the Philippines, Singapore and Thailand - plus Australia, China, Hong Kong, Japan, Korea, New Zealand and Taiwan. These 12 economies have, to substantially varying degrees, freely operating and developed financial markets.

This paper does not revisit tests of the degree to which financial markets are integrated (see Bayoumi 1997 and de Brouwer 1999 for two recent surveys). It is generally accepted that financial markets in the market-based economies of east Asia are relatively highly integrated with financial markets in the rest of the world. Indeed, in its recent report on the activities of highly leveraged institutions in emerging markets, the Financial Stability Forum Study Group on Market Dynamics (2000) notes that hedge funds, investment banks and other financial institutions were active in many of the region's financial markets precisely because they were (and mostly still are) open and liquid.

Financial integration is evident in most regional economies in a number of ways relatively open capital accounts, large but volatile capital inflows to emerging east Asia (and large capital outflows from Japan), the satisfaction of various interest rate parity conditions (notably covered interest parity), increased effects of international 
(that is, US) interest rates on domestic interest rates, falling saving and investment correlations, and improved consumption smoothing through access to foreign capital (Hung and Tong 1996; Bayoumi 1997; de Brouwer 1999).

This is not to say that the financial crises in east Asia and subsequently Russia and Latin America - as well as the seizing-up of bond markets in the United States towards the end of 1998 - have not affected the degree of financial integration in the region. In the first place, it is probably fair to say that the binary on-off nature of capital inflows to emerging east Asia has adversely affected integration: price formation and asset arbitrage are effected by financial flows and if cross-border capital flows dry up, then an important mechanism for stable price formation and linkage is lost. As shown in Figure 1, gross capital inflows to Asia appeared to all but disappear in 1998. While they have recovered to some degree for some countries, like Korea (Figure 2), they have not done so for all countries, most strikingly Indonesia (Figure 3). The composition of gross capital inflows has also shifted, with loan gross inflows replaced by direct investment.

Figure 1: Emerging Market Country Gross Capital Inflows

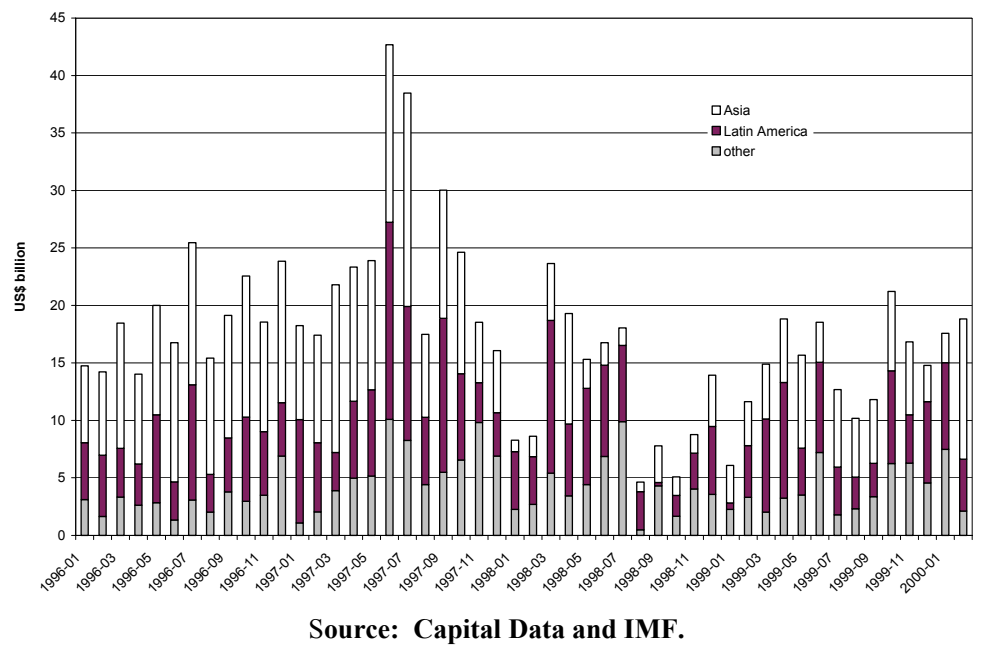


Figure 2: Korea Gross Capital Inflows



Figure 3: Indonesia Gross Capital Flows



Source: Capital Data and IMF.

Moreover, the regulatory regime has changed in a number of economies. This is most obvious in Malaysia, where capital controls were imposed and the exchange rate fixed on 1 and 2 September 1998. The controls on the repatriation of proceeds from investment in Malaysia's stock market have subsequently been eased, but the other capital controls introduced at the time remain, including the controls on the international use of the ringgit. Other countries in the region, like Indonesia, Taiwan and Thailand, have also introduced some controls, most especially on the international use of their currencies. More specifically, as in Singapore, they limit currency swap positions in order to limit large speculative short positions in their currencies (Fane 2000; de Brouwer 2000a). But, at the same time, controls on FDI have been eased in Korea and Thailand. 
This paper examines patterns of commonness in regional financial prices over the five years from 1995 to 1999 . There are many ways to determine how much financial prices have in common. The paper uses principal components analysis and elementary factor analysis to determine the common variability in regional financial prices. While particular economic models and data-generating processes underlie the formation of financial prices and returns, the turmoil in regional financial markets makes it particularly difficult to derive and estimate these as a means of identifying common generating mechanisms. Moreover, given that variability is probably one of the main characteristics of regional financial markets and prices in recent years, it may be more appropriate to assess how much of this variability has been common to regional financial prices (Forbes and Rigobon 1999).

The results of this analysis need to be interpreted cautiously - just because a set of financial prices moves together more in some period, it does not follow that financial integration or openness has improved. Communality - that is, the variance that one variable has in common with a set of other variables - is a sufficient but not necessary condition for financial integration. Greater co-movement between financial prices could arise, for example, if there were fewer idiosyncratic shocks or more common shocks in the period under consideration. Indeed, markets may have become less open but there may have been more common shocks, generating more co-movement between financial prices. Moreover, as Masson (1999) outlines, these common shocks may have been in the form of pure contagion, that is financial market contagion unrelated to cross-market effects based on common shocks to countries' macroeconomic fundamentals. In short, there is no unique mapping from communality to financial openness.

That said, it is important not to go to the other extreme and say that there is no information about the integration of financial markets in common variations in financial prices. Common patterns of variability in financial prices may have information about the structure and interaction of financial markets in a region. For example, communality in regional short-term interest rates is likely to be higher if regional monetary authorities follow a common monetary policy, which will be the case if they have similar policy objectives and face similar initial conditions and economic cycles. In the same way, common stock price or exchange rate movements may contain information about common economic or financial structures in countries. 
If communality appears systematically, at different times in the presence of different shocks, then it is more likely to reveal information about the way financial markets are integrated than if communality appears randomly and without order. If there are systematically common patterns of variation, then it is more likely that basic economic and financial structures are similar. Moreover, even if the interpretation of common variability requires caution, it is still interesting and useful to identify the common variability in financial prices.

The paper is intended as a preliminary "first-pass" assessment of high frequency regional financial data. It is structured in the following way. Section 2 applies principal component analysis and Section 3 applies common factor analysis to interest rates, stock prices and nominal exchange rates (relative to the US dollar) in 12 economies in the region. ${ }^{2}$ Section 3.1 examines common factors in east Asia as a whole, and Section 3.2 examines common factors in particular sub-groups. Section 4 examines the relative influence of Japan and the United States on the variability of financial prices in individual countries in the region. Section 5 uses cointegration analysis to test for long-run relationships in the asset prices of countries in the region. Section 6 summarises the results, provides a policy discussion, and concludes the paper. Definitions, sources and some basic statistical features of the data are provided in Appendix 1, and graphs are shown in Appendix 2.

\section{Principal Components Analysis}

This section uses principal components analysis to assess the evolution of the pattern of financial integration before, during and after the east Asian financial crisis of 1997 and 1998. By estimating the linear combinations of variables which maximise their variance, the method of principal components provides information about the dimensions or the strength of interdependence among these variables (Ghosh 1991). It provides a useful way to identify common information in a set of financial prices, and hence provides some insight into changing patterns of financial integration.

For a set of $p$ stationary variables, $x$, with sample size, $n$,

2 The principal components and common factors are estimated using Stata 6. 


$$
x=\left[\begin{array}{ccc}
x_{11} & \ldots & x_{1 p} \\
\vdots & & \vdots \\
x_{n 1} & & x_{p n}
\end{array}\right]
$$

it is possible to construct a set of $p$ new variables, $w$, which are the principal components of equation (1),

$$
w_{j}=c_{j 1} x_{1}+c_{j 2} x_{2}+\ldots+c_{j p} x_{p}, j=1,2, \ldots, p
$$

The variable $w_{l}$, for example, is the first principal component and explains the highest possible proportion of the total variance among the variables, given that that the $c_{1 j}$ coefficients are chosen to maximise the variance of $w_{l}$ subject to the normalisation condition,

$$
c_{11}^{2}+c_{12}^{2}+\ldots+c_{1 p}^{2}=1
$$

Since changing the measurement of the variables changes the principal components, the variables are standardised to have unit variance - each variable is set to its original value less its mean, and is then divided by its standard deviation. By construction, the principal components are independent.

Tables 1 to 3 below show the proportion of the total variation among various daily financial prices - interest rates, stock prices and exchange rates respectively explained by the first principal component. The closer the number is to 1 , the more common is the variation in the financial prices.

The main principal component is shown for four east Asian regional sub-groupings the ASEAN-5 (Indonesia, Malaysia, the Philippines, Singapore and Thailand), the NE-Asia-3 (Japan, Korea and Taiwan), the China-3 (China, Hong Kong and Taiwan), and Australia and New Zealand (ANZ) - and for key aggregations of these groups. They are shown for the period 1995 to 1999 as a whole, and for sub-periods. In particular, estimates are shown for each calendar year and for a nominated pre-crisis period (2 January 1996 to 30 June 1997), crisis period (1 July 1997 to 31 October 1998), and post-crisis period (1 November 1998 to 31 December 1999). The latter classifications are subjective but not arbitrary. The Asian financial crisis period is deemed to have started with the devaluation of the baht in early July 1997 (Kaminsky and Schmukler 1999), and ended with the sharp unwinding of short positions in east Asian financial markets following the Russian debt default and near-collapse of Long- 
Term Capital Management in October 1998. While this was certainly not the end of the financial crises that gripped the US and Latin American markets in the December quarter of 1998, it is widely accepted as the occasion of substantial relief in east Asian financial markets (Financial Stability Forum Study Group on Market Dynamics, 2000).

The analysis in this section uses daily data. While the "noise" content of asset prices is greater at higher frequencies, using daily data enables the analyst to capture the common impact of news as it affects asset markets (Kaminsky and Schmukler 1999). (The way daily, as opposed to weekly or monthly data affects some of the statistics will be discussed below.) Interest rates, exchange rates and stock prices are differenced once to make them stationary (Appendix 1).

Table 1: Main Principal Component of Daily Interest Rate Changes

\begin{tabular}{lccccc}
\hline \hline & ASEAN-5 & NE Asia & Asia-ANZ & ANZ & East Asia \\
\hline $1995-1999$ & 0.24 & 0.36 & 0.15 & 0.61 & 0.12 \\
1995 & 0.24 & 0.37 & 0.16 & 0.62 & 0.15 \\
1996 & 0.25 & 0.38 & 0.16 & 0.66 & 0.15 \\
1997 & 0.25 & 0.38 & 0.15 & 0.59 & 0.14 \\
1998 & 0.27 & 0.34 & 0.18 & 0.62 & 0.15 \\
1999 & 0.26 & 0.36 & 0.15 & 0.57 & 0.14 \\
Pre-crisis period & 0.24 & 0.37 & 0.15 & 0.64 & 0.15 \\
Crisis period & 0.24 & 0.37 & 0.16 & 0.61 & 0.13 \\
Post-crisis period & 0.26 & 0.36 & 0.16 & 0.57 & 0.13 \\
\hline \hline
\end{tabular}

Notes: ASEAN-5 includes Indonesia, Malaysia, the Philippines, Singapore and Thailand; NE Asia includes Japan, Korea and Taiwan; and ANZ includes Australia and New Zealand. The pre-crisis period is 2 January 1996 to 30 June 1997, the crisis period is 1 July 1997 to 31 October 1998, and the post-crisis period is 1 November 1998 to 31 December 1999.

Table 2: Main Principal Component of Daily Stock Market Changes

\begin{tabular}{lcccccc}
\hline \hline & ASEAN-5 & China-3 & NE Asia & Asia-ANZ & ANZ & East Asia \\
\hline $1995-1999$ & 0.50 & 0.42 & 0.41 & 0.33 & 0.77 & 0.33 \\
1995 & 0.57 & 0.41 & 0.38 & 0.35 & 0.73 & 0.31 \\
1996 & 0.50 & 0.40 & 0.37 & 0.31 & 0.71 & 0.30 \\
1997 & 0.48 & 0.39 & 0.42 & 0.30 & 0.84 & 0.32 \\
1998 & 0.54 & 0.48 & 0.44 & 0.39 & 0.75 & 0.38 \\
1999 & 0.44 & 0.42 & 0.43 & 0.32 & 0.70 & 0.31 \\
Pre-crisis & 0.43 & 0.39 & 0.36 & 0.26 & 0.71 & 0.26 \\
Crisis & 0.54 & 0.45 & 0.44 & 0.37 & 0.82 & 0.37 \\
Post-crisis & 0.44 & 0.42 & 0.42 & 0.31 & 0.68 & 0.30 \\
\hline \hline
\end{tabular}

Notes: ASEAN-5 includes Indonesia, Malaysia, the Philippines, Singapore and Thailand; China-3 includes China (B stocks), Hong Kong and Taiwan; NE Asia includes Japan, Korea and Taiwan; and ANZ includes Australia and New Zealand. The daily change is the first difference of the log of the index. The pre-crisis period is 2 January 1996 to 30 June 1997, the crisis period is 1 July 1997 to 31 October 1998, and the post-crisis period is 1 November 1998 to 31 December 1999. 
Table 3: Main Principal Component of Daily Exchange Rate Changes

\begin{tabular}{lccccc}
\hline \hline & ASEAN-5 & NE Asia & Asia-ANZ & ANZ & East Asia \\
\hline $1995-1999$ & 0.53 & 0.46 & 0.39 & 0.71 & 0.33 \\
1995 & 0.44 & 0.53 & 0.40 & 0.65 & 0.32 \\
1996 & 0.33 & 0.50 & 0.32 & 0.60 & 0.27 \\
1997 & 0.46 & 0.40 & 0.30 & 0.71 & 0.28 \\
1998 & 0.61 & 0.54 & 0.48 & 0.72 & 0.43 \\
1999 & 0.45 & 0.52 & 0.33 & 0.75 & 0.28 \\
Pre-crisis period & 0.24 & 0.45 & 0.22 & 0.62 & 0.18 \\
Crisis period & 0.56 & 0.47 & 0.41 & 0.72 & 0.37 \\
Post-crisis period & 0.42 & 0.53 & 0.33 & 0.74 & 0.27 \\
\hline \hline
\end{tabular}

Notes: ASEAN-5 includes Indonesia, Malaysia, the Philippines, Singapore and Thailand; NE Asia includes Japan, Korea and Taiwan; and ANZ includes Australia and New Zealand. The daily change is the first difference of the log of the exchange rate. The pre-crisis period is 2 January 1996 to 30 June 1997, the crisis period is 1 July 1997 to 31 October 1998, and the post-crisis period is 1 November 1998 to 31 December 1999.

There are three notable outcomes.

First, some of the sub-groupings have higher common variation than others. In general, financial prices in Australia and New Zealand have more in common than for the other sub-groupings. Indeed, as shown in Table 4 in relation to stock prices, they have more variation in common than for any other pair of countries in the region, except Hong Kong and Singapore. With respect to share prices in particular and exchange rates to a lesser degree, the regional sub-grouping with the next highest common variation is the ASEAN-5, followed by the NE-Asia-3 and the China-3, although the differences between northeast and southeast Asia should not be overstated.

Table 4: Main Principal Component, Stock Market Changes, 95-99

\begin{tabular}{|c|c|c|c|c|c|c|c|c|c|c|c|c|}
\hline & 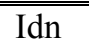 & 2 Mys & 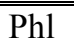 & Sgp & Thl & Kor & Jpn & Twn & 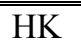 & "Chn & Aus & $\overline{\mathrm{NZZ}}$ \\
\hline Idn & -- & -- & -- & -- & -- & -- & - & -- & -- & -- & -- & -- \\
\hline Mys & 0.65 & -- & -- & -- & -- & -- & -- & -- & -- & -- & -- & -- \\
\hline $\mathrm{Phl}$ & 0.69 & 0.62 & -- & -- & -- & -- & -- & -- & -- & -- & -- & -- \\
\hline Sgp & 0.74 & 0.72 & 0.76 & -- & -- & -- & -- & -- & -- & -- & -- & -- \\
\hline Thl & 0.70 & 0.67 & 0.68 & 0.74 & -- & -- & -- & -- & -- & -- & -- & -- \\
\hline Kor & 0.58 & 0.59 & 0.60 & 0.61 & 0.63 & -- & -- & -- & -- & -- & -- & -- \\
\hline Jpn & 0.60 & 0.60 & 0.58 & 0.65 & 0.59 & 0.56 & -- & -- & -- & -- & -- & -- \\
\hline Twn & 0.60 & 0.59 & 0.60 & 0.63 & 0.58 & 0.56 & 0.57 & -- & -- & -- & -- & -- \\
\hline HK & 0.69 & 0.69 & 0.70 & 0.83 & 0.69 & 0.60 & 0.68 & 0.62 & -- & -- & -- & -- \\
\hline Chn & 0.56 & 0.59 & 0.60 & 0.61 & 0.57 & 0.53 & 0.54 & 0.56 & 0.63 & -- & -- & -- \\
\hline Aus & 0.63 & 0.64 & 0.66 & 0.72 & 0.63 & 0.60 & 0.69 & 0.60 & 0.76 & 0.58 & -- & -- \\
\hline $\mathrm{NZ}$ & 0.61 & 0.61 & 0.66 & 0.68 & 0.61 & 0.60 & 0.61 & 0.60 & 0.67 & 0.56 & 0.77 & -- \\
\hline
\end{tabular}


Second, east Asian stock prices and exchange rates respectively appear to have moved more closely together in the crisis period than in the non-crisis periods, and they appear to have had more in common after the crisis than before. The former feature reflects the fact that the financial crisis affected all of east Asia, albeit to varying degrees. The latter feature may reflect the fact that the recovery in financial markets from the crisis has also been broadly based in the region, and so caution is necessary in interpreting this result as a general proposition that financial integration has increased.

Third, the main principal components for exchange rates and stock prices appear to be broadly similar in magnitude. However, the main principal component for short-term market interest rates are, numerically at least, considerably smaller than for other financial prices. This is most apparent in the case for the ASEAN-5. The lower main principal components for interest rates may reflect the fact that market rates are dominated by the stance of domestic monetary policy, which is set to domestic requirements and can differ substantially between countries. As shown by the comparative constancy in the magnitude of the main principal component, domestic monetary policies differed somewhat between countries both during crisis and noncrisis periods.

Differences in monetary policy are also apparent in the Australia-New Zealand main principal component for interest rate changes. The monetary policy reaction in Australia and New Zealand to the depreciation of their currencies in 1998 was very different: based on its target of a monetary conditions index, the Reserve Bank of New Zealand encouraged market interest rates to rise as the exchange rate depreciated during 1997 and 1998, while the Reserve Bank of Australia kept interest rates unchanged as the Australian dollar depreciated. Not surprisingly, the main principal component between changes in Australian and New Zealand interest rates declined over this period.

\section{Common Factor Analysis}

Factor analysis is another way to assess common elements in financial variables. This has been examined for some regional financial prices. Dungey (1997) and Dungey and Martin (1999), for example, provide a latent factor analysis of exchange rates. 
Dungey, Martin and Pagan (1999) provide a dynamic factor analysis of regional bond yields. $^{3}$

Factor analysis is concerned with finding a small number, $q$, of common but orthogonal factors that linearly reconstruct the original $p$ variables,

(4) $x_{i j}=z_{i 1} b_{1 j}+z_{i 2} b_{2 j}+\ldots+z_{i q} b_{q j}+e_{i j}$,

where $x_{i j}$ is observation $i$ of variable $j$ (standardised to have unit variance), $z_{i k}$ is observation $i$ of the common factor $k, b_{k j}$ is the set of linear factor loadings, and $e_{i j}$ is variable $j$ 's unique factor (that is, a factor uncorrelated with the common factors).

The factor loading is the weight for each factor, and measures the contribution of the factor to the common variance of the data series.

While there are also other methods, a variable's communality - that is, the variance it has in common with a set of other variables - is estimated using the squared multiple correlation coefficients of the original variable, and hence is based on the prediction of the original covariance matrix (Rummel 1970). Given that the variables have been standardised to have unit variances, a variable's communality is also equal to the sum of the squared loading coefficients for the $q$ factors. ${ }^{4}$ Subtracting the variable's communality from 1 provides a measure of its "uniqueness", as reported in subsequent tables (Rummel 1970). A variable's uniqueness is the percentage of its variance that is not explained by the common factors.

\subsection{Common Factors in East Asia}

Tables 5, 6 and 7 report the main eigenvalues and factor loadings from factor analysis of daily changes in east Asian interest rates, stock price and exchange rate respectively, over different time periods in the past 5 years. ${ }^{5}$ The aim of this exercise

\footnotetext{
3 It is well known that financial prices contain autoregressive heteroscedasticity and serial correlation, especially at high frequencies. Like Dungey (1997), these are not explicitly addressed in this paper but will form part of future modelling work.

While there are several methods to estimate factor models (Rummel 1970; Stata, 1999), this paper uses the principal factor method (that is, estimating the communalities using squared multiple correlation coefficients). Other methods were also used, such as iteration and maximum likelihood, and, in general, the results are not qualitatively different and so are not reported. The factor loadings reported in the paper are the unrotated loadings unless otherwise stated.

The very smallest eigenvalues, generally those below 0.1 , are not reported.
} 
is to identify common regional responses in financial prices. A subjective assessment of such responses is represented by the shaded portions in the tables.

In the case of interest rate changes (Table 5), there appear to be very few common regional factors. The largest eigenvalue is associated with an Australia-New Zealand common factor, which also seems to be present in the three sub-periods. During the crisis period, the sign is opposite to other countries, suggesting that interest rates in these countries were jointly less affected by the crisis. The second largest eigenvalue for the period as whole is an Indonesia-Philippines common factor, but it is only present in the crisis sub-period. The Indonesia-Philippines connection is consistent with other work which shows that interest rates in these two countries have tended to carry a larger risk premium (Das Gupta and Das Gupta 1994; de Brouwer 1999). The third identifiable factor is a Japan-Korea factor, but this seems to be relatively unstable - the sign on the factor loadings changes over time.

The uniqueness coefficients are high compared to those on stock price and exchange rate changes, indicating a relatively high degree of idiosyncrasy in interest rate innovations. Given the independence of monetary policy, this is not unexpected.

Table 5: Factor Analysis of Daily Interest Rate Changes

\begin{tabular}{|c|c|c|c|c|c|c|c|c|c|c|c|}
\hline \multirow{2}{*}{\multicolumn{2}{|c|}{ Eigenvalues }} & \multicolumn{10}{|c|}{ Factor Loadings } \\
\hline & & Jpn & Kor & Twn & Sgp & Mys & Thl & Idn & Phl & Aus & $\mathrm{NZ}$ \\
\hline \multicolumn{12}{|l|}{ 1995-99 } \\
\hline 1 & 0.28 & 0.02 & 0.01 & -0.10 & -0.03 & -0.11 & 0.04 & -0.06 & 0.00 & 0.36 & 0.35 \\
\hline 2 & 0.22 & -0.05 & 0.07 & 0.06 & -0.16 & 0.03 & 0.08 & 0.29 & 0.30 & -0.00 & 0.06 \\
\hline 3 & 0.14 & -0.15 & -0.23 & -0.07 & 0.16 & 0.14 & 0.05 & 0.05 & 0.05 & 0.03 & 0.02 \\
\hline uniqueness & & 0.98 & 0.94 & 0.98 & 0.95 & 0.97 & 0.99 & 0.91 & 0.91 & 0.87 & 0.87 \\
\hline \multicolumn{12}{|l|}{ Pre-crisis } \\
\hline 1 & 0.56 & 0.06 & 0.03 & -0.24 & 0.04 & 0.00 & 0.22 & 0.25 & -0.06 & 0.40 & 0.47 \\
\hline 2 & 0.25 & 0.07 & 0.18 & 0.12 & 0.22 & 0.19 & 0.07 & 0.23 & 0.21 & -0.12 & 0.00 \\
\hline 3 & 0.20 & 0.12 & 0.22 & 0.15 & -0.06 & -0.18 & -0.04 & -0.13 & 0.15 & 0.17 & 0.02 \\
\hline 4 & 0.13 & -0.17 & -0.08 & 0.08 & 0.06 & -0.12 & 0.19 & 0.06 & 0.06 & 0.10 & -0.13 \\
\hline uniqueness & & 0.95 & 0.91 & 0.90 & 0.94 & 0.92 & 0.91 & 0.87 & 0.93 & 0.79 & 0.76 \\
\hline \multicolumn{12}{|l|}{ Crisis } \\
\hline 1 & 0.34 & 0.05 & -0.02 & 0.02 & 0.06 & 0.09 & 0.00 & 0.06 & 0.01 & -0.37 & -0.38 \\
\hline 2 & 0.27 & -0.10 & 0.04 & 0.04 & -0.13 & 0.06 & 0.04 & 0.35 & 0.36 & -0.08 & 0.02 \\
\hline 3 & 0.17 & 0.19 & 0.25 & 0.05 & -0.21 & -0.17 & 0.04 & 0.02 & -0.00 & 0.02 & 0.01 \\
\hline 4 & 0.11 & 0.06 & 0.07 & 0.27 & 0.02 & 0.10 & -0.16 & 0.07 & -0.04 & 0.01 & -0.00 \\
\hline uniqueness & & 0.95 & 0.93 & 0.93 & 0.93 & 0.95 & 0.97 & 0.87 & 0.87 & 0.86 & 0.86 \\
\hline \multicolumn{12}{|l|}{ Post-crisis } \\
\hline 1 & 0.40 & 0.10 & 0.16 & -0.13 & -0.01 & 0.14 & -0.24 & -0.15 & 0.22 & 0.21 & 0.39 \\
\hline 2 & 0.36 & 0.11 & 0.03 & -0.03 & 0.37 & -0.32 & 0.01 & -0.04 & -0.26 & 0.05 & 0.18 \\
\hline 3 & 0.17 & -0.21 & 0.23 & -0.10 & 0.02 & 0.00 & 0.20 & 0.04 & -0.00 & 0.14 & -0.01 \\
\hline 4 & 0.13 & 0.00 & 0.13 & 0.25 & 0.12 & 0.04 & -0.08 & 0.15 & 0.07 & 0.03 & -0.03 \\
\hline Uniqueness & & 0.93 & 0.90 & 0.91 & 0.85 & 0.88 & 0.90 & 0.95 & 0.88 & 0.93 & 0.81 \\
\hline
\end{tabular}

Notes: the pre-crisis period is 2 January 1996 to 30 June 1997, the crisis period is 1 July 1997 to 31 October 1998, and the post-crisis period is 1 November 1998 to 31 December 1999; the factor loadings were unrotated except for the crisis period which were rotated using the varimax technique. 
In the case of stock price changes (Table 6), there is only one key common factor and it represents all markets in the region examined. It is best interpreted as a global stock market factor, rather than strictly as an Asia-only one, since the factor loading on the US share price is a relatively large 0.59 if that variable is included in the set (not shown). That said, while the global factor is present in all three sub-periods, the loading factors are generally highest in the crisis period, reflecting the fact that regional stock markets were sold down in unison in the crisis. By way of contrast, the US factor loading in both the pre-crisis and post-crisis periods is unchanged at 0.63 (not shown). While stock markets are globally integrated, the amplitude of the effect varies region by region, country by country.

The uniqueness/communality coefficients vary substantially by country. On the one hand, the uniqueness coefficients are lowest (communality greatest) for regional stock markets that are generally regarded as internationally open regional financial centres, like Singapore (0.33), Hong Kong (0.38) and Australia (0.41). The stock markets of China (0.85), Korea (0.82) and Taiwan (0.89), on the other hand, have the least in common with the other stock markets in the region. The stock markets of Malaysia, New Zealand, Thailand and the Philippines sit somewhere in the middle of these two groups. Japan's stock market (0.74) appears to be more similar to the more idiosyncratic stock markets of northeast Asia than the open and integrated stock markets of the region.

Apart from the main common factor, there are two other factors for regional subgroups. One is an Australian-New Zealand factor. The stock markets of both countries have common shocks that exist for no other countries in the region. This occurs in the full sample and all sub-periods. In the crisis period, stock prices in these two countries did not fall by as much as elsewhere in the region, as indicated by the positive signs in the "global market" factor loading and negative signs in the Australia-New Zealand factor loading.

The other is a China factor. This is evident in the full sample and the post-crisis subperiod. China's stock prices are the odd one out in the region - its "global market" factor loading is the smallest of the 12 economies examined, and is only nonnegligible in the crisis period. This suggests that while China's stock market was 
affected by the region's financial crisis ( a common sell-off of stock), it is not well integrated with world markets. This is consistent with China's relatively closed capital account and restrictions on foreign participation in China's stock market. China's stock market, however, does share common variability with other Chinese stock markets in the region, namely, Hong Kong and Taiwan. The presence of a China factor, however, does not indicate the direction of the common variability, that is, whether it is from China to Hong Kong and Taiwan or the other way round.

Table 6: Factor Analysis of Daily Stock Price Changes

\begin{tabular}{|c|c|c|c|c|c|c|c|c|c|c|c|c|c|}
\hline \multirow{2}{*}{\multicolumn{2}{|c|}{ Eigenvalues }} & \multicolumn{12}{|c|}{ Factor Loadings } \\
\hline & & Jpn & Kor & Twn & $\mathrm{HK}$ & Chn & Sgp & Mys & Thl & Idn & Phl & Aus & $\mathrm{NZ}$ \\
\hline \multicolumn{14}{|l|}{ 1995-99 } \\
\hline 1 & 3.77 & 0.42 & 0.39 & 0.32 & 0.76 & 0.28 & 0.80 & 0.52 & 0.57 & 0.57 & 0.60 & 0.67 & 0.56 \\
\hline 2 & 0.45 & 0.17 & -0.02 & 0.05 & 0.05 & -0.05 & -0.16 & -0.17 & -0.23 & -0.21 & -0.10 & 0.37 & 0.32 \\
\hline 3 & 0.15 & -0.21 & 0.08 & 0.03 & -0.17 & -0.00 & -0.06 & -0.06 & 0.05 & 0.05 & 0.16 & 0.00 & 0.19 \\
\hline 4 & 0.14 & -0.08 & -0.12 & 0.07 & 0.11 & 0.25 & 0.02 & -0.06 & -0.13 & -0.06 & 0.12 & -0.04 & -0.02 \\
\hline Uniqueness & & 0.74 & 0.82 & 0.89 & 0.38 & 0.85 & 0.33 & 0.69 & 0.61 & 0.62 & 0.59 & 0.41 & 0.54 \\
\hline \multicolumn{14}{|l|}{ Pre-crisis } \\
\hline 1 & 2.84 & 0.27 & 0.01 & 0.13 & 0.74 & 0.17 & 0.74 & 0.61 & 0.35 & 0.63 & 0.37 & 0.64 & 0.44 \\
\hline 2 & 0.53 & 0.16 & 0.22 & 0.11 & 0.17 & 0.03 & -0.19 & -0.23 & -0.30 & -0.17 & -0.10 & 0.32 & 0.30 \\
\hline Uniqueness & & 0.90 & 0.95 & 0.97 & 0.42 & 0.97 & 0.42 & 0.58 & 0.79 & 0.58 & 0.86 & 0.49 & 0.72 \\
\hline \multicolumn{14}{|l|}{ Crisis } \\
\hline 1 & 4.70 & 0.47 & 0.48 & 0.44 & 0.75 & 0.48 & 0.83 & 0.56 & 0.61 & 0.63 & 0.67 & 0.77 & 0.64 \\
\hline 2 & 0.59 & -0.21 & 0.00 & -0.02 & 0.00 & 0.11 & 0.19 & 0.18 & 0.21 & 0.25 & 0.13 & -0.43 & -0.40 \\
\hline Uniqueness & & 0.74 & 0.77 & 0.81 & 0.38 & 0.76 & 0.27 & 0.66 & 0.59 & 0.55 & 0.54 & 0.23 & 0.43 \\
\hline \multicolumn{14}{|l|}{ Post-crisis } \\
\hline 1 & 2.97 & 0.50 & 0.42 & 0.29 & 0.68 & 0.05 & 0.75 & 0.28 & 0.62 & 0.39 & 0.47 & 0.61 & 0.47 \\
\hline 2 & 0.38 & -0.31 & 0.08 & 0.07 & -0.21 & 0.16 & -0.00 & -0.03 & 0.24 & 0.13 & 0.30 & -0.19 & 0.04 \\
\hline 3 & 0.30 & 0.03 & -0.15 & 0.25 & 0.07 & 0.26 & -0.16 & -0.21 & -0.15 & -0.06 & 0.13 & 0.16 & 0.10 \\
\hline 4 & 0.19 & 0.06 & 0.06 & 0.04 & 0.17 & 0.20 & 0.08 & -0.04 & 0.07 & -0.10 & -0.03 & -0.16 & -0.26 \\
\hline Uniqueness & & 0.65 & 0.79 & 0.85 & 0.46 & 0.87 & 0.41 & 0.88 & 0.54 & 0.82 & 0.67 & 0.54 & 0.70 \\
\hline
\end{tabular}

Notes: the pre-crisis period is 2 January 1996 to 30 June 1997, the crisis period is 1 July 1997 to 31 October 1998, and the post-crisis period is 1 November 1998 to 31 December 1999.

In the case of exchange rate changes (Table 7), there is also one main common factor which can be interpreted as a regional factor. It is strongest in the crisis period, but is not restricted to that sub-period. It is narrowest in its coverage in the pre-crisis period, where the main common factor only affects the currencies of Japan, Korea, Taiwan, Malaysia and Singapore.

The uniqueness in exchange rates also varies substantially. Over the full period, the uniquenesses are lowest (communalities highest) for the Singapore dollar and the ringgit (before it was fixed on 1 September 1998), followed by the Philippine peso, rupiah, baht, Australian dollar, yen, New Taiwan dollar, New Zealand dollar, and won. That said, the uniqueness in exchange rates is also generally lower in the post- 
crisis period than in the pre-crisis period. This may reflect the general shift towards genuinely flexible exchange rate regimes in the region during the crisis period, although this does not explain the fall in uniqueness for the Australian and New Zealand dollars.

Table 7: Factor Analysis of Daily Exchange Rate Changes

\begin{tabular}{|c|c|c|c|c|c|c|c|c|c|c|c|}
\hline \multirow{2}{*}{\multicolumn{2}{|c|}{ Eigenvalues }} & \multicolumn{10}{|c|}{ Factor Loadings } \\
\hline & & $\Delta$ yen & $\Delta$ won & $\Delta \$ N T$ & $\Delta \$ S$ & $\Delta \mathrm{Rm}$ & $\Delta \mathrm{Bt}$ & $\Delta \mathrm{Rp}$ & $\Delta$ Peso & $\Delta \$ \mathrm{~A}$ & $\Delta \$ N Z$ \\
\hline \multicolumn{12}{|c|}{ 1995-99 } \\
\hline 1 & 2.63 & 0.41 & 0.20 & 0.48 & 0.77 & 0.72 & 0.58 & 0.51 & 0.52 & 0.39 & 0.24 \\
\hline 2 & 0.52 & 0.20 & -0.06 & -0.08 & 0.00 & -0.20 & -0.15 & -0.11 & -0.05 & 0.41 & 0.48 \\
\hline 3 & 0.29 & 0.34 & 0.06 & 0.21 & 0.14 & -0.09 & -0.08 & -0.19 & -0.14 & -0.13 & -0.11 \\
\hline 4 & 0.12 & -0.03 & 0.22 & 0.16 & -0.17 & -0.08 & 0.03 & 0.00 & 0.08 & 0.05 & -0.01 \\
\hline \multicolumn{2}{|c|}{ Uniqueness } & 0.68 & 0.90 & 0.69 & 0.36 & 0.43 & 0.63 & 0.69 & 0.70 & 0.66 & 0.70 \\
\hline \multicolumn{12}{|c|}{ Pre-crisis } \\
\hline 1 & 1.06 & 0.69 & 0.29 & 0.26 & 0.56 & 0.23 & 0.17 & 0.08 & 0.03 & -0.10 & 0.10 \\
\hline 2 & 0.35 & 0.00 & -0.06 & -0.10 & 0.09 & -0.03 & -0.01 & 0.00 & 0.04 & 0.41 & 0.40 \\
\hline \multicolumn{2}{|c|}{ Uniqueness } & 0.52 & 0.91 & 0.92 & 0.67 & 0.95 & 0.97 & 0.99 & 1.00 & 0.82 & 0.83 \\
\hline \multicolumn{12}{|c|}{ Crisis } \\
\hline 1 & 3.12 & 0.51 & 0.19 & 0.52 & 0.81 & 0.75 & 0.58 & 0.52 & 0.54 & 0.59 & 0.31 \\
\hline 2 & 0.66 & 0.36 & -0.07 & -0.10 & -0.04 & -0.28 & -0.23 & -0.14 & -0.06 & 0.39 & 0.45 \\
\hline 3 & 0.21 & 0.16 & 0.20 & 0.29 & -0.02 & -0.07 & -0.02 & -0.16 & -0.07 & -0.02 & -0.14 \\
\hline \multicolumn{2}{|c|}{ Uniqueness } & 0.59 & 0.92 & 0.64 & 0.34 & 0.36 & 0.60 & 0.68 & 0.69 & 0.50 & 0.68 \\
\hline \multicolumn{12}{|c|}{ Post-crisis } \\
\hline 1 & 2.05 & 0.45 & 0.39 & 0.42 & 0.63 & $\mathrm{n} / \mathrm{a}$ & 0.71 & 0.41 & 0.56 & 0.27 & 0.25 \\
\hline 2 & 0.66 & -0.04 & -0.12 & -0.13 & -0.06 & $\mathrm{n} / \mathrm{a}$ & -0.08 & -0.05 & -0.09 & 0.55 & 0.55 \\
\hline 3 & 0.39 & 0.27 & 0.27 & 0.31 & -0.10 & $\mathrm{n} / \mathrm{a}$ & -0.29 & -0.21 & -0.04 & 0.04 & 0.03 \\
\hline \multicolumn{2}{|c|}{ Uniqueness } & 0.72 & 0.76 & 0.71 & 0.59 & $\mathrm{n} / \mathrm{a}$ & 0.41 & 0.78 & 0.68 & 0.63 & 0.63 \\
\hline
\end{tabular}

Notes: n/a indicates not applicable; the pre-crisis period is 2 January 1996 to 30 June 1997, the crisis period is 1 July 1997 to 31 October 1998, and the post-crisis period is 1 November 1998 to 31

December 1999.

There are two other sets of exchange rate common factors of interest. One is the bynow familiar Australia-New Zealand (ANZ) common factor. As for stock prices, the ANZ factor has the second largest eigenvalue in the system. The loadings on these two currencies in the main common factor are positive, indicating that they were subject to the same influences as the other currencies in the region. But the loadings on them in the Australia-New Zealand common factor are positive while the loadings on the other currencies - apart from the yen - are negative, indicating that, along with the yen, the two currencies moved less than (most of) the other currencies in the region in the crisis. 
The other common factor in innovations to the exchange rate is a Korea-JapanTaiwan factor. It is evident in some form in all the periods examined. From 1995 to 1999, it appears as two bilateral factors - a yen-\$NT factor and a won-\$NT factor but in the sub-periods these merge into one factor.

There are two general comments about the factor analysis of financial prices conducted above. The first is that, not surprisingly, the factor loadings change with rotations, and so there is an element of judgment and subjectivity in which loadings are reported. The unrotated loadings are reported unless otherwise stated. While rotations change the loadings, however, they do not substantively change the qualitative interpretation of the results: the interpretations are relatively robust to the sample period and data set.

The other comment is that it is widely accepted that financial prices contain considerable noise at high frequencies, and this is certainly true with daily data. This impacts on the results here by making the uniquenesses higher (communalities lower), not usually by changing the structure of the relationships. The exercise was repeated, for example, using weekly changes in the exchange rate (not reported). In this case, the pattern of common factors was the same but the uniquenesses fell (communalities rose) by up to 30 percentage points, with a modal improvement of about 20 percentage points. Reducing the frequency in this case reduced idiosyncratic noise but it did not affect the interpretation. However, repeating the exercise with monthly data over a much longer sample period may do so, as different common factors may come into play.

\subsection{Common Factors in East Asian Sub-Groups}

The analysis above indicates that there is a common regional factor in east Asian financial prices. It also shows that some sub-groups also exist. In particular, the results suggest that Australia and New Zealand constitute their own group, and that there are connections (albeit weaker) within the market economies of northeast Asia and the China-3.

This section attempts to explore the issue of common factors in sub-groups in more detail. The question posed is: what is the minimum number of factors needed to reconstruct the financial prices of the various sub-groupings in the region? The 
presumption underlying the question is that the fewer the number of factors required, the more that group can be said to constitute a region in its own right. This should not be necessarily be interpreted as indicating that the common factor is exclusive to the region. If there is a common global factor in share markets, for example, a single common factor for a sub-group may simply be identifying the global factor in the group. This section seeks to determine formally the number of common factors in stock prices and exchange rates from 1995 to 1999 in the market-based economies of ASEAN, northeast Asia, and greater China.

The results are reported in Table 8 . The test statistic for the number of factors is derived from a maximum likelihood estimation of the factors (Rummel 1970; Stata 1999). It is approximately chi-squared distributed (Bartlett 1951) and its marginal significance is shown in the final column of Table 8 . The results indicate that there are two factors in innovations to ASEAN-5 stock prices and exchange rates, but that this reduces to one common factor if the Philippines is excluded from the set. When the Philippines is included and two factors estimated, the loading on the second factor for the Philippines is considerably larger than for the other four countries. In northeast Asia, there appears to be a single common factor in stock prices and in the exchange rate.

Table 8: Common Factors in Regional Sub-groups, 1995-99

\begin{tabular}{|c|c|c|c|c|c|}
\hline Region & $\begin{array}{l}\text { Financial } \\
\text { price }\end{array}$ & $\begin{array}{c}\text { Eigenvalue } 1 \\
\text { (proportion) }\end{array}$ & $\begin{array}{c}\text { Eigenvalue } 2 \\
\text { (proportion) }\end{array}$ & $\begin{array}{l}\text { Hypothesis: } \\
\text { no. of factors }\end{array}$ & $\begin{array}{c}\text { Marginal } \\
\text { significance }\end{array}$ \\
\hline ASEAN-5 & Stock Price & 0.79 & 0.29 & 2 vs. more & 0.06 \\
\hline ASEAN-5 & Stock Price & 0.79 & 0.29 & 1 vs. more & $0.00 * *$ \\
\hline $\begin{array}{l}\text { ASEAN-5 less } \\
\text { the Philippines }\end{array}$ & Stock Price & 1.00 & & 1 vs. more & 0.15 \\
\hline ASEAN-5 & Exchange rate & 0.89 & 0.11 & 2 vs. more & 0.37 \\
\hline ASEAN-5 & Exchange rate & 0.89 & 0.11 & 1 vs. more & $0.00 * *$ \\
\hline $\begin{array}{l}\text { ASEAN-5 less } \\
\text { the Philippines }\end{array}$ & Exchange rate & 1.00 & & 1 vs. more & 0.68 \\
\hline NE-Asia & Stock Price & 1.00 & & 1 vs. more & 0.34 \\
\hline NE-Asia & Exchange rate & 1.00 & & 1 vs. more & 0.68 \\
\hline Greater China & Stock Price & 1.00 & & 1 vs. more & $0.02 *$ \\
\hline Greater China & Exchange rate & 1.00 & & 1 vs. more & 0.91 \\
\hline
\end{tabular}

Notes: ** and * indicate significant at the 1 and 5 per cent levels; for the purposes of having sufficiently large sub-groups to conduct statistical tests, NE Asia consists of China, Korea, Japan and Taiwan, and Greater China consists of China, Hong Kong, Singapore and Taiwan. 


\section{Spheres of Influence: The US or Japan?}

Chinn and Frankel (1992) first raised the issue of whether the relative influence of the US and Japan in international financial markets has changed over time, with the aim of determining whether non-Japan east Asia had started to become part of a "yen bloc". They examined how the effects of Japanese and US interest rates on non-Japan east Asian interest rates altered through time, and reported that the Japan effect had increased in some cases. This has been pursued also by Glick and Moreno (1994) and de Brouwer (1999). Tse and $\mathrm{Ng}$ (1997) explore some aspects of regional exchange rates.

This section takes up the issue of relative influence using factor analysis of daily regional interest rates and stock prices in the past five years. Tables 9 and 11 show the uniqueness coefficient from common factor analysis of daily changes in each country's interest rate and stock price respectively, and the corresponding change in the interest rate or stock price from Japan or the United States. The pair with the lower uniqueness (higher communality) factor indicates whether the market in the United States or Japan has more in common with the market in the country under analysis. This is represented by the shaded portion in the tables.

Table 9: East Asian Interest Rate Changes Uniqueness relative to interest rate changes in the USA and Japan

\begin{tabular}{lcc|cc|cc|cc}
\hline \hline & \multicolumn{2}{c}{$1995-99$} & \multicolumn{2}{c|}{ Pre-Crisis Period } & \multicolumn{2}{c|}{ Crisis Period } & \multicolumn{2}{c}{ Post-Crisis Period } \\
& USA & Japan & USA & Japan & USA & Japan & USA & Japan \\
\hline Korea & 0.97 & 0.97 & 0.99 & 0.95 & 0.93 & 0.96 & 0.99 & 0.96 \\
Taiwan & 0.98 & 0.98 & 0.98 & 0.98 & 0.98 & 0.97 & 0.93 & 0.99 \\
Indonesia & 0.99 & 0.99 & 0.99 & 0.98 & 0.99 & 0.99 & 0.99 & 0.97 \\
Malaysia & 0.99 & 0.99 & 0.97 & 0.99 & 0.97 & 0.98 & 0.99 & 0.99 \\
Philippines & 0.99 & 0.99 & 0.99 & 0.99 & 0.99 & 0.98 & 0.98 & 0.98 \\
Singapore & 0.99 & 0.99 & 0.98 & 0.98 & 0.98 & 0.99 & 0.96 & 0.95 \\
Thailand & 0.99 & 0.99 & 0.99 & 0.99 & 0.99 & 0.98 & 0.98 & 0.98 \\
Australia & 0.99 & 0.99 & 0.98 & 0.99 & 0.98 & 0.99 & 0.99 & 0.99 \\
New Zealand & 0.97 & 0.99 & 0.99 & 0.97 & 0.96 & 0.98 & 0.91 & 0.96 \\
\hline \hline
\end{tabular}

Notes: the pre-crisis period is 2 January 1996 to 30 June 1997, the crisis period is 1 July 1997 to 31 October 1998, and the post-crisis period is 1 November 1998 to 31 December 1999.

In terms of interest rates (Table 9), neither the United States nor Japan is obviously more important than the other in terms of having common variability with interest rate in non-Japan east Asia. In the five years from 1995 to 1999, US rates have more in common than Japanese rates with rates in other countries in the region, except for 
Indonesia, Malaysia and the Philippines. Nor is any pattern discernible in the subsamples, and there is some flip-flopping between sub-samples.

The lack of a clear pattern for interest rates is not surprising. In the first place, it is typical of the empirical literature that interest-rate connections between countries are fuzzy (Glick and Romeno 1994; de Brouwer 1999). Moreover, if countries follow independent monetary policies - which most of these economies do since they mostly have flexible exchange rates - then it does not necessarily follow that variability in interest rates need be related between countries (Woo and Hirayama 1995).

The uniqueness coefficients in Table 9 are mostly very close to one, implying that common daily effects are swamped by domestic factors. Table 10 presents a broader perspective, by conducting the analysis over a 10-year period with monthly interest rate changes. In this case, the uniqueness coefficients on local interest rate changes falls, but, again, there is no clear pattern over time about the relative importance of interest rates in Japan and the United States. Indeed, in terms of number of countries, Japanese rates had less in common with rates in the region than US rates did in the second half of the 1990s than in the first half.

Table 10: East Asian Interest Rate Changes, Monthly Uniqueness relative to interest rate changes in the USA and Japan

\begin{tabular}{l|cc|cc|cc|cc|cc}
\hline \hline & \multicolumn{2}{|c|}{$1990-94$} & \multicolumn{2}{c|}{$1995-99$} & \multicolumn{2}{c|}{ Pre-Crisis } & \multicolumn{2}{c|}{ Crisis Period } & \multicolumn{2}{c}{ Post-Crisis } \\
& USA & Japan & USA & Japan & USA & Japan & USA & Japan & USA & Japan \\
\hline Korea & 0.93 & 0.85 & 0.87 & 0.77 & 0.81 & 0.86 & 0.76 & 0.40 & 0.81 & 0.99 \\
Taiwan & 0.99 & 0.94 & 0.86 & 0.96 & 0.58 & 0.80 & 0.91 & 0.81 & 0.95 & 0.81 \\
Indonesia & 0.92 & 0.96 & 0.99 & 0.98 & 0.94 & 0.96 & 0.96 & 0.97 & 0.99 & 0.88 \\
Malaysia & 0.96 & 0.96 & 0.84 & 0.94 & 0.61 & 0.96 & 0.42 & 0.87 & 0.96 & 0.97 \\
Philippines & 0.94 & 0.95 & 0.94 & 0.94 & 0.85 & 0.92 & 0.81 & 0.89 & 0.87 & 0.78 \\
Singapore & 0.72 & 0.95 & 0.97 & 0.90 & 0.98 & 0.94 & 0.88 & 0.89 & 0.98 & 0.99 \\
Thailand & 0.95 & 0.74 & 0.88 & 0.88 & 0.87 & 0.73 & 0.72 & 0.82 & 0.91 & 0.74 \\
Australia & 0.76 & 0.85 & 0.86 & 0.97 & 0.92 & 0.90 & 0.76 & 0.70 & 0.95 & 0.88 \\
New Zealand & 0.84 & 0.77 & 0.93 & 0.96 & 0.93 & 0.90 & 0.64 & 0.91 & 0.98 & 0.97 \\
\hline \hline
\end{tabular}

Notes: the pre-crisis period is 2 January 1996 to 30 June 1997, the crisis period is 1 July 1997 to 31 October 1998, and the post-crisis period is 1 November 1998 to 31 December 1999.

In contrast to interest rates, however, the pattern for stock price innovations is substantially clearer (Table 11). In this case, it is the United States that consistently matters more than Japan, with the uniqueness of regional stock prices consistently lower (communality consistently higher) when the US stock price is included instead of the Japanese stock price. In the full sample period, this is the case for every 
economy in the sample, although for particular sub-samples, the Japanese stock price is marginally superior. The effect of the United States is particularly striking for Australia and New Zealand.

The fact that the Dow consistently matters more than the Nikkei in explaining stock price variability in east Asia would come as no surprise to practitioners in regional financial markets. Day by day, stock markets around the world look to US markets for direction. What is interesting in this case is that the Nikkei provides little in addition to US stock markets. Given the differences in time zones, the observation used for the Dow is that of the previous day. The observation for the Nikkei, however, is that of the same day. Even though the Nikkei has already absorbed information about the previous day's developments in the US market, and even though it is subject to the same real-time shocks (since it is essentially trading in the same time zone), Japanese stock prices still generally have less in common with regional stock prices than those in the United States.

Table 11: East Asian Daily Stock Market Changes Uniqueness relative to stock price changes in the USA and Japan

\begin{tabular}{lc|c|c|c|cc|cc}
\hline \hline & \multicolumn{2}{c|}{$1995-99$} & \multicolumn{2}{c|}{ Pre-Crisis Period } & \multicolumn{2}{c|}{ Crisis Period } & \multicolumn{2}{c}{ Post-Crisis Period } \\
& USA & Japan & USA & Japan & USA & Japan & USA & Japan \\
\hline Korea & 0.89 & 0.93 & 0.96 & 0.98 & 0.87 & 0.90 & 0.87 & 0.92 \\
Taiwan & 0.88 & 0.92 & 0.98 & 0.99 & 0.78 & 0.88 & 0.89 & 0.90 \\
Hong Kong & 0.74 & 0.75 & 0.66 & 0.83 & 0.76 & 0.71 & 0.73 & 0.68 \\
Indonesia & 0.83 & 0.88 & 0.80 & 0.95 & 0.84 & 0.85 & 0.79 & 0.89 \\
Malaysia & 0.82 & 0.88 & 0.82 & 0.90 & 0.79 & 0.86 & 0.88 & 0.84 \\
Philippines & 0.80 & 0.90 & 0.86 & 0.98 & 0.78 & 0.87 & 0.78 & 0.92 \\
Singapore & 0.75 & 0.80 & 0.76 & 0.89 & 0.73 & 0.78 & 0.76 & 0.75 \\
Thailand & 0.87 & 0.89 & 0.94 & 0.99 & 0.86 & 0.87 & 0.85 & 0.85 \\
Australia & 0.59 & 0.74 & 0.61 & 0.86 & 0.53 & 0.61 & 0.62 & 0.75 \\
New Zealand & 0.63 & 0.87 & 0.76 & 0.94 & 0.50 & 0.82 & 0.75 & 0.90 \\
\hline \hline
\end{tabular}

Notes: the pre-crisis period is 2 January 1996 to 30 June 1997, the crisis period is 1 July 1997 to 31 October 1998, and the post-crisis period is 1 November 1998 to 31 December 1999.

\section{Long-run relationships}

The common factor analysis in Section 4 focuses largely on patterns of short-run commonness in regional asset prices. Using the same daily data from 1995 to 1999, this section tests whether meaningful long-run relationships exist between regional financial prices using cointegration analysis.

Based on the maximal eigenvalue and trace statistics for the number of cointegrating vectors using the Johansen multivariate technique, there appear to be at most three 
cointegrating vectors for interest rates, two for stock prices, and three for exchange rates. ${ }^{6}$ The country loadings in the cointegrating vectors and the marginal significance of the error correction variable in the error correction model (ECM) for each country's asset price are shown for interest rates, stock prices and exchange rates in Tables 12,13 and 14 respectively. The ECMs are estimated using OLS and the variances are corrected for heteroscedasticity using White's method. The shaded areas show the countries for which the ECM is significant at the 5 per cent level.

There are three points of interest in these results. The first is that the signs in the cointegrating vectors are not uniform - some are positive, some are negative, making it difficult to identify meaningful long-run relationships between variables. This may be the result of the relatively short five-year sample period. Cointegration analysis is more useful with lower frequency data and longer time frames. If the aim is to assess the nature of financial interaction in east Asia before and after the crisis, then using cointegration analysis is premature.

The second observation is that the main regional grouping that appears is between the crisis countries - Indonesia, Korea, Malaysia and Thailand in the case of interest rates (with the opposite sign for Malaysia), and Indonesia, Korea, the Philippines,

Singapore and Thailand for exchange rates (with the opposite sign for Singapore and Thailand). For the sample period as whole, the crisis period dominates. Shifting the analysis to sub-periods is unlikely to help, because long-run relationships are even less likely to be well identified over shorter sample periods.

The third observation is that the results for stock prices are very different if the United States is excluded from the sample. In this case, there is only one cointegrating vector and the error correction term is only significant for the Philippines and Thailand. The

\footnotetext{
$6 \quad$ For interest rates, the maximal eigenvalue statistic for one relative to two cointegrating vectors is 64.60, which is significant at the $10(62.8)$ but not 5 (66.17) per cent level of significance. The trace statistic for two relative to three cointegrating vectors is 210.32 , which significant at the 10 (206.37) but not 5 (213.4) per cent levels of significance. For stock prices, the maximal eigenvalue statistic for zero relative to one cointegrating vector is 87.57 , which is significant at both the $10(74.25)$ and 5 (77.73) per cent level of significance. The trace statistic for one relative to two cointegrating vectors is 304, which is significant at both the 10 (294.14) and 5 (302.38) per cent levels of significance. For exchange rates, the maximal eigenvalue statistic for one relative to two cointegrating vectors is 59.96, which is significant at the $10(57.37)$ but not 5 (60.48) per cent level of significance. The trace statistic for two relative to three cointegrating vectors is 185.85 , which is significant at both the $10(168.23)$ and 5 (174.88) per cent levels of significance. The results were obtained using Microfit 4.0. The VAR lag length is set at 4 .
} 
inference from this is that the US stock market is the key determinant of regional stock prices, which is consistent with the analysis in Sections 3 and 4.

Table 12: CointegratingVectors for Interest Rates

\begin{tabular}{lccc|ccc}
\hline \hline & \multicolumn{2}{c}{ Cointegrating Vector. countrv loading } & \multicolumn{3}{c}{ Marginal significance of error correction } \\
\hline & No. 1 & No. 2 & No. 3 & No. 1 & No. 2 & No. 3 \\
\hline Japan & -0.057 & -0.006 & -0.043 & 0.52 & 0.15 & 0.71 \\
Korea & 0.015 & 0.004 & -0.001 & 0.00 & 0.03 & 0.15 \\
Taiwan & -0.019 & 0.028 & -0.018 & 0.27 & 0.00 & 0.30 \\
Indonesia & 0.001 & 0.001 & 0.004 & 0.00 & 0.93 & 0.16 \\
Malaysia & -0.010 & 0.015 & -0.008 & 0.04 & 0.00 & 0.13 \\
Philippines & 0.007 & -0.005 & -0.004 & 0.10 & 0.68 & 0.92 \\
Singapore & -0.014 & -0.033 & 0.008 & 0.62 & 0.07 & 0.08 \\
Thailand & 0.014 & -0.007 & 0.001 & 0.00 & 0.23 & 0.70 \\
Australia & 0.082 & -0.014 & -0.008 & 0.47 & 0.02 & 0.91 \\
New Zealand & -0.038 & 0.007 & 0.006 & 0.10 & 0.27 & 0.00 \\
United States & -0.046 & 0.065 & 0.075 & 0.74 & 0.08 & 0.00 \\
\hline \hline
\end{tabular}

Table 13: CointegratingVectors for Stock Prices

\begin{tabular}{lcc|cc}
\hline \hline & \multicolumn{1}{c|}{ Cointegrating Vector. countrv loading } & \multicolumn{2}{c}{ Marginal significance of error correction } \\
\hline & No. 1 & No. 2 & No. 1 & No. 2 \\
\hline Japan & 0.121 & 0.030 & 0.50 & 0.71 \\
Korea & 0.079 & 0.123 & 0.00 & 0.70 \\
Taiwan & -0.098 & -0.117 & 0.78 & 0.05 \\
Hong Kong & -0.168 & 0.072 & 0.03 & 0.61 \\
Indonesia & -0.266 & 0.160 & 0.08 & 0.20 \\
Malaysia & 0.406 & -0.299 & 0.00 & 0.20 \\
Philippines & -0.205 & 0.230 & 0.08 & 0.00 \\
Singapore & -0.092 & -0.032 & 0.42 & 0.29 \\
Thailand & -0.055 & -0.120 & 0.62 & 0.01 \\
Australia & -0.803 & -1.188 & 0.48 & 0.14 \\
New Zealand & 0.059 & 0.298 & 0.01 & 0.15 \\
United States & 1.214 & 0.443 & 0.00 & 0.29 \\
\hline
\end{tabular}

Table 14: CointegratingVectors for Exchange Rates

\begin{tabular}{lccc|ccc}
\hline \hline & \multicolumn{2}{c}{ Cointegrating Vector. countrv loading } & \multicolumn{3}{c}{ Marginal significance of error correction } \\
\hline & No. 1 & No. 2 & No. 3 & No. 1 & No. 2 & No. 3 \\
\hline Japan & 0.078 & 0.369 & 0.023 & 0.47 & 0.00 & 0.05 \\
Korea & -0.022 & 0.273 & 0.006 & 0.00 & 0.07 & 0.15 \\
Taiwan & 0.485 & -1.569 & 0.310 & 0.40 & 0.89 & 0.20 \\
Indonesia & -0.150 & -0.048 & -0.016 & 0.00 & 0.30 & 0.60 \\
Philippines & -0.571 & 0.131 & 1.054 & 0.00 & 0.25 & 0.01 \\
Singapore & 0.059 & 0.553 & 0.957 & 0.04 & 0.45 & 0.45 \\
Thailand & 0.300 & -0.182 & -0.642 & 0.00 & 0.37 & 0.50 \\
Australia & 0.657 & -0.082 & -0.072 & 0.98 & 0.23 & 0.57 \\
New Zealand & 0.173 & 0.654 & -0.419 & 0.87 & 0.03 & 0.28 \\
\hline \hline
\end{tabular}




\section{Conclusion}

This paper has explored the pattern of financial integration in east Asian financial markets by assessing common variabilities between the financial prices in different countries and time periods in the five years from 1995 to 1999. Because there is not a unique mapping between common variability and financial integration, caution is needed in interpreting the results. Moreover, it is a preliminary assessment only. With that in mind, there are three main results.

First, even though the pattern of common variability depends to some extent on the financial prices themselves, countries and time periods, there is a relatively high degree of commonality in financial price variability in east Asia. Individual financial markets clearly do not exist in a vacuum, which reflects the relatively high degree of financial integration that exists in east Asia.

Common variability in the region is most prevalent and robust in stock market price indices but this reflects global, rather than just regional-specific influences. Common variability is also evident in exchange rates but is considerably less so for interest rates, which reflects the independence of monetary policy in countries in the region. Common variability in stock prices and exchange rates is not just a product of the financial crisis: while the common element in financial price variability generally reached its peak in the crisis period, it is by no means restricted to that period. Common patterns of variability in regional stock prices and exchange rates may also reflect the fact that market participants tend to trade regional assets together. For example, east Asian emerging assets are traded as elements of an emerging markets portfolio, and the Australian and New Zealand dollars are traded together as "commodity currencies" (see the Report of the Financial Stability Forum Study Group on Market Dynamics 2000).

Despite the ructions to financial markets caused by the crisis, they are still integrated: patterns of common variability have remained largely intact. The main exception appears to be China's stock market, but it does not appear to have been well integrated with world stock markets in the first place.

Second, there are particular sub-groups of countries which systematically have additional common variability in their financial prices. The strongest of these is Australia and New Zealand - a common factor exists for all their financial prices in 
all sample periods. As measured by the main principal component, the common variation in Australian and New Zealand financial prices is also consistently higher than for almost any other pair of countries.

Patterns of common variability also exist, albeit less robustly, for stock prices and exchange rates for Japan, Korea and Taiwan, and for the stock markets of China, Hong Kong and Taiwan. For stock prices and exchange rates in northeast Asia and for stock prices in greater China, only one common factor is needed to reconstruct these financial prices.

The ASEAN-5 is a more diverse group. While the proportion of common variability in ASEAN-5 financial prices is generally higher than for northeast Asia and greater China, there is no ASEAN factor in additional to the east-Asian factor. The closest that the ASEAN-5 comes to this is a small Indonesia- Philippines factor in interest rates. Moreover, there are generally at least two common factors in ASEAN-5 stock prices and exchange rates, although this reduces to one if the Philippines is excluded. It would seem unlikely that the financial prices of ASEAN-10 could be reconstructed in a few factors.

Third, there is little support in these tests for the view that non-Japan east Asia is part of a "yen bloc". Neither the United States nor Japan is consistently more important in sharing the variability of short-term interest rates in the region, on either a daily or monthly basis. This is not surprising since most countries in the region have had flexible exchange rates and followed independent monetary policies. But the story is very different in regard to stock prices. Stock prices in the region consistently have more variability in common with the Dow than the Nikkei, although the relative importance of the Nikkei has increased since the crisis, which may be due to the coincidence of the recovery in emerging east Asia and progress in banking and financial reform in Japan.

These results suggest two policy implications. First, global integration underpins financial integration in the region. For example, the common factor in regional stock markets is global rather than Asian specific. Similarly, developments in the US financial markets remain vital to developments locally, and this has not changed with the crisis. As policymakers think about regional institution building (for example, an Asian Monetary Fund) and common currency arrangements (for example, an Asian 
Currency Unit), the challenge is to do this in a way that remains outward-focussed and does not undermine integration with global financial markets.

Second, if common institutions and financial market arrangements are to proceed in east Asia, they can do so on a coordinated multilateral basis or in a step-wise manner starting with some groups first and then with others. This paper has not tested whether east Asia, or parts of it, form an optimal common currency area (see Eichengreen and Bayoumi 1999; de Brouwer 2000b). But the results in the paper suggest that if this process is pursued in a step-wise manner, the most obvious place to start may be Australia and New Zealand. The evidence of a separate "common area" from financial prices is less clear for northeast Asia, and even less so for the ASEAN5 (let alone the ASEAN-10). 


\section{Appendix 1: Data Definitions, Sources and Statistical Features}

\section{A1.1 Data Definitions}

Interest rates are defined as 3-month interbank mid-market interest rates for Australia, Hong Kong, Japan, Malaysia, New Zealand, Taiwan and Thailand. They are defined as the 1-month interbank market rate for Indonesia, the 91-day NCD rate for Korea, the 91-day Treasury Bill rate for the Philippines, and the 3-month secondary market Treasury Bill yield for the United States.

Share prices are defined as the All Ordinaries Index for Australia, the Shanghai BShare Price Index for China, the Hang Seng Index for Hong Kong, the Jakarta Composite Index for Indonesia, the Nikkei Index for Japan, the South Korean Composite Stock Price Index for Korea, the Kuala Lumpur Composite for Malaysia, the Top 40 Index for New Zealand, the Manila Composite Index for the Philippines, the Straits Times (New) Price Index for Singapore, the Weighted Stock Price Index for Taiwan, the Bangkok Stock Exchange Index for Thailand, the Dow Jones Industrial Index for the United States.

Exchange rates are defined in terms of US dollars.

\section{A1.2 Data Sources}

Daily data are sourced from Datastream.

\section{A1.3 Stationarity}

The order of integration of the time series is assessed using the familiar augmented Dickey Fuller (ADF) test (Dickey and Fuller 1979) over the full sample period, with the critical values drawn from MacKinnon (1994). The null hypothesis is that there is a unit root in the time series. The test equation includes a constant, time trend and 4 lags of the independent variable. The ADF statistics are estimated using the dfuller command in Stata-6 (Stata 1999, Reference A-G, 298-300). Table A1.3.1 reports the marginal significance for the key $\mathrm{Z}(\mathrm{t})$ statistic (ie., lagged level of the dependent variable): a reading of 0.01 and 0.90 , for example, indicates that the null hypothesis is rejected at the 1 and 90 per cent levels of significance respectively. Stock prices and exchange rates appear to be difference stationary (US and Australian stock price indices appear to have deterministic rather than stochastic trends in this period). While interest rates also appear to be difference stationary, the result is different when allowance is made for breaks in the mean (not reported).

Table A1.3.1: Augmented Dickey-Fuller Z(t) Test Statistics

\begin{tabular}{lcccccccccccccc}
\hline \hline & Aus & Chn & Ind & HK & Jpn & Kor & Mys & NZ & Phl & Sgp & Twn & Thl & USA \\
\hline Interest rate & & & & & & & & & & & & \\
Level & 0.99 & n/a & 0.91 & 0.88 & 0.04 & 0.72 & 0.95 & 0.67 & 0.54 & 0.21 & 0.34 & 0.68 & 0.34 \\
First Difference & 0.00 & n/a & 0.00 & 0.00 & 0.00 & 0.00 & 0.00 & 0.00 & 0.00 & 0.00 & 0.00 & 0.00 & 0.00 \\
\hline Stock Price & & & & & & & & & & & & \\
Level & 0.02 & 0.66 & 0.80 & 0.88 & 0.78 & 0.99 & 0.91 & 0.30 & 0.68 & 0.99 & 0.60 & 0.96 & 0.06 \\
First difference & 0.00 & 0.00 & 0.00 & 0.00 & 0.00 & 0.00 & 0.00 & 0.00 & 0.00 & 0.00 & 0.00 & 0.00 & 0.00 \\
\hline Exchange Rate & & & & & & & & & & & & \\
Level & 0.80 & $\mathrm{n} / \mathrm{a}$ & 0.78 & $\mathrm{n} / \mathrm{a}$ & 0.98 & 0.81 & 0.55 & 0.55 & 0.82 & 0.41 & 0.93 & 0.80 & $\mathrm{n} / \mathrm{a}$ \\
First difference & 0.00 & $\mathrm{n} / \mathrm{a}$ & 0.00 & 0.00 & 0.00 & 0.00 & 0.00 & 0.00 & 0.00 & 0.00 & 0.00 & 0.00 & 0.00 \\
\hline \hline
\end{tabular}

Notes: the figure indicates the marginal significance of the stationarity statistic, $\mathrm{Z}(\mathrm{t})$; $\mathrm{n} / \mathrm{a}$ indicates not applicable. 
Appendix 2: Graphs of the Data

\section{Interest Rates}

Figure A2.1.1: ASEAN-5

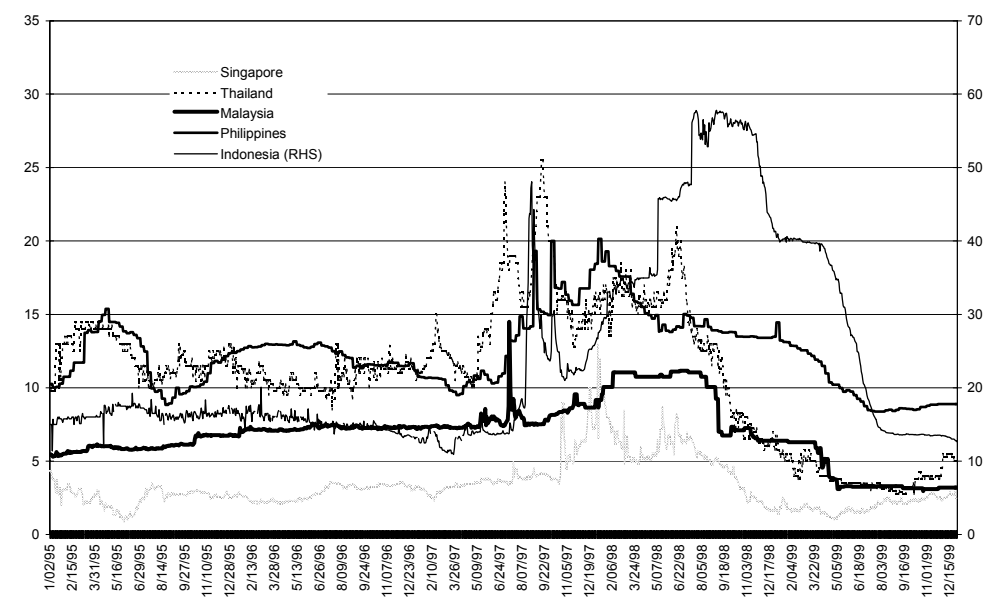

Figure A2.1.2: Japan, Korea, Taiwan and Hong Kong



Figure A2.1.3: Australia, New Zealand and the United States

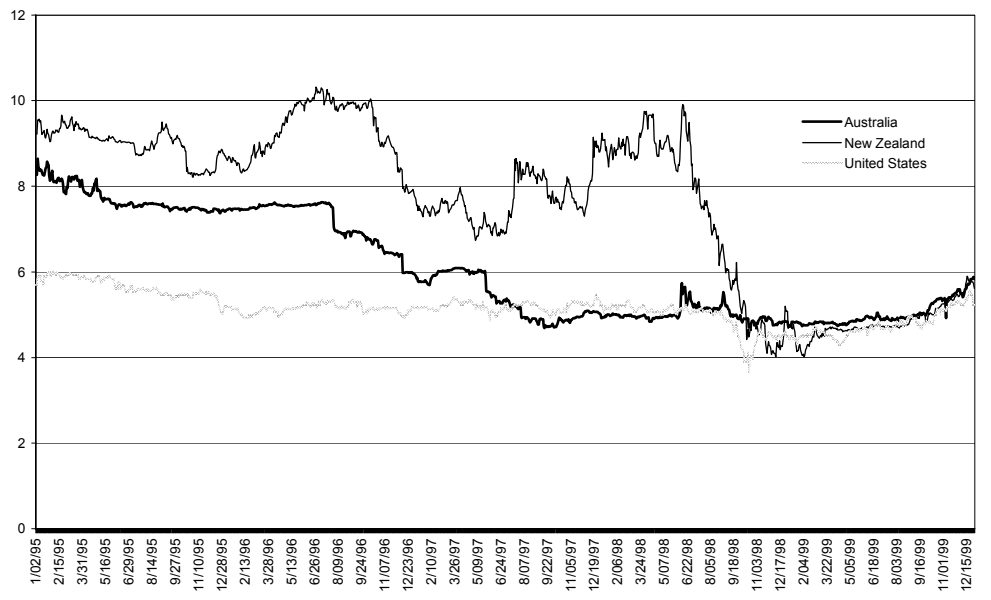


Stock Prices

Figure A2.2.1: ASEAN-5

Index, 1995 $=100$

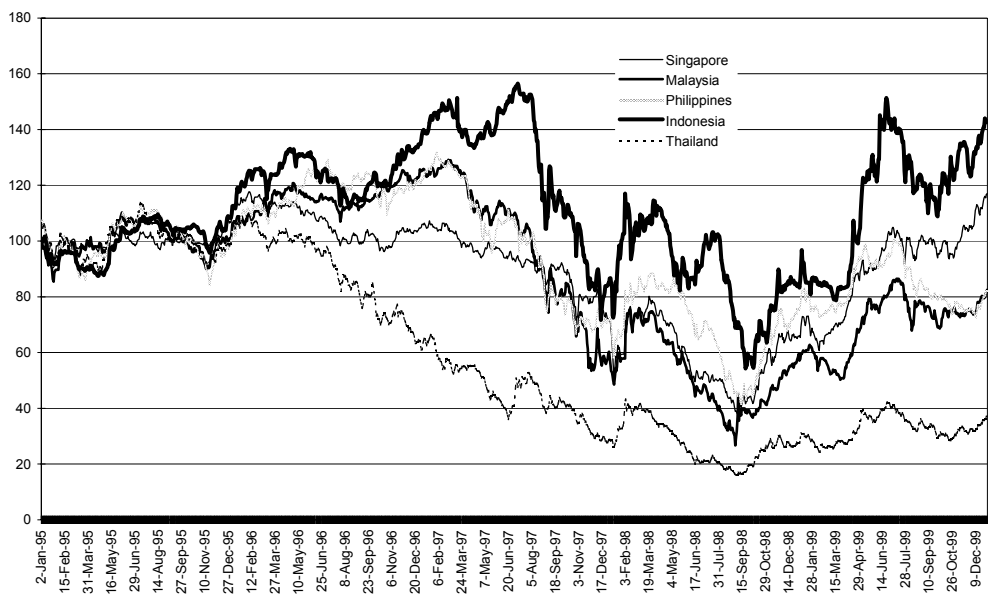

Figure A2.2.2: China, Hong Kong, Korea, Taiwan and Japan Index, 1995 $=100$



Figure A2.2.3: Australia, New Zealand and the United States Index, 1995 $=100$

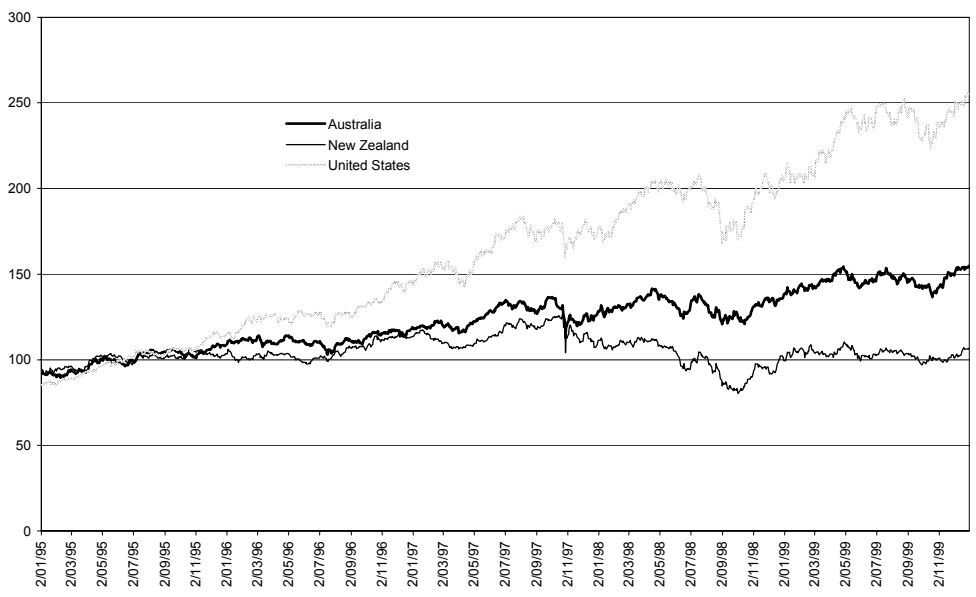


Exchange Rates

Figure A2.3.1: ASEAN-5

Index, $1995=100$

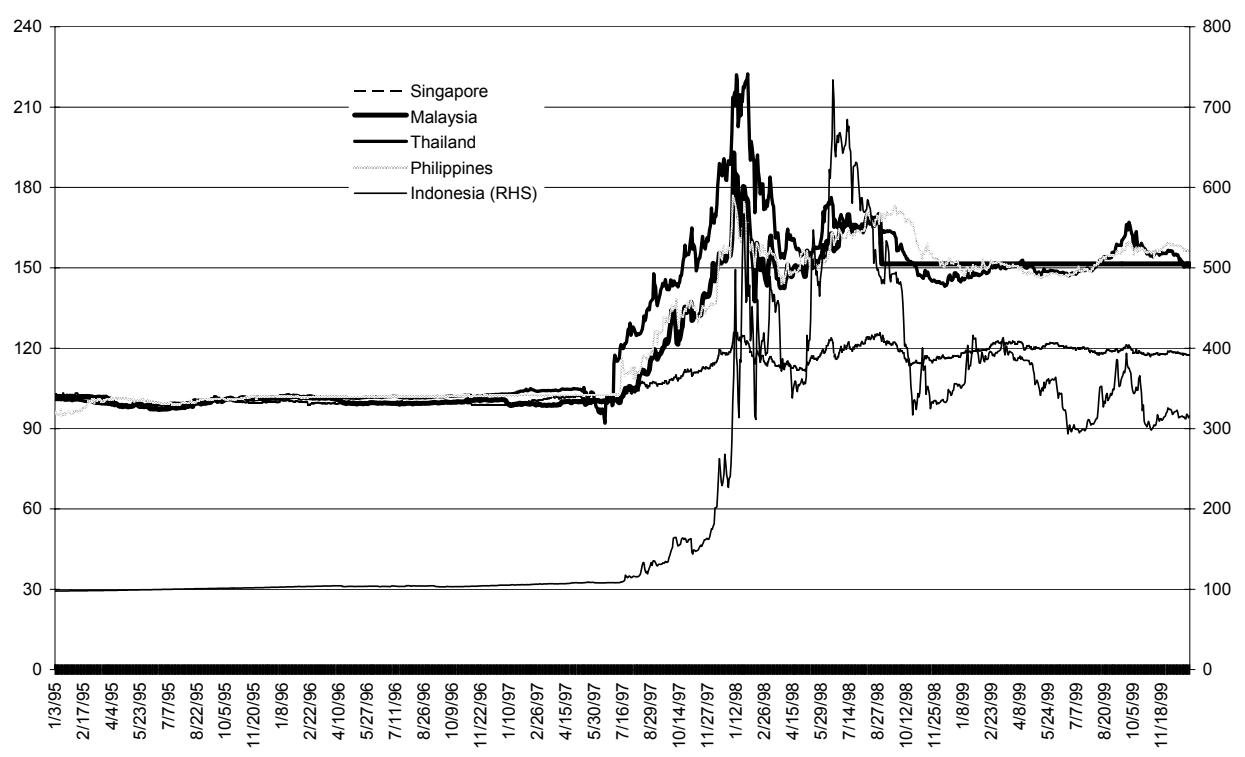

Figure A2.3.1: Japan, Korea, Taiwan, Australia and New Zealand Index, $1995=100$






\section{References}

Bartlett, M. (1951), "The Effect of Standardization on a $\chi^{2}$ Approximation in Factor Analysis", Biometrika, 38, 337-344.

Bayoumi, T. (1997), Financial Integration and Real Activity, University of Michigan Press, Ann Arbour.

Clemente, L. (1994), "Investing in Asia's Emerging Equity Market", Columbia Journal of World Business, 29(2), Summer, 92-111.

Das Gupta, D. and B. Das Gupta (1994), “Interest Rates in Open Economies: Real Interest Rate Parity, Exchange Rates, and Country Risk in Industrial and Developing Countries", World Bank Policy Research Working Paper No. 1283.

de Brouwer, G.J. (1999), Financial Integration in East Asia, Cambridge University Press, Cambridge.

de Brouwer, G.J. (2000a), Hedge Funds and Emerging Markets, mimeo.

de Brouwer, G.J. (2000b), “Common Currency Arrangements for East Asia: Does A Formal Common-Basket Peg Make Economic Sense?”, mimeo.

Dickey, D.A. and W.A. Fuller (1979), "Distribution of the Estimators for Autoregressive Time Series with a Unit Root", Journal of the American Statistical Association, 74, 427-431.

Dungey, M. (1997), “A Multivariate Approach to Decomposing Volatility in Bilateral Exchange Rates", Australian National University Working Paper in Economics and Econometrics No. 320.

Dungey, M. and V.L. Martin (1999), "Contagion in the East Asian Currency Crisis", mimeo.

Dungey, M., V.L. Martin and A.R. Pagan (1999), “A Multivariate Latent Factor Decomposition of International Bond Spreads", mimeo.

Eichengreen, B. and T. Bayoumi (1999), "Is Asia an Optimal Currency Area? Can It Become One?", in Stefan Collignon, Jean Pisani-Ferry and Yung Chul Park (eds.), Exchange Rate Policies in Emerging Asian Countries, Routledge, London, 347-366.

Fane, G. (2000), Capital Mobility, Exchange Rates and Economic Crises, mimeo.

Financial Stability Forum Study Group on Market Dynamics (2000), Report of the Market Dynamics Study Group of the Financial Stability Forum Working Group on Highly Leveraged Institutions, March, Washington, D.C.

Forbes, K. and R. Rigobon (1999), "No Contagion, Only Interdependence:

Measuring Stock Market Co-Movements”, NBER Working Paper No. 7267.

Glick, R. and R. Moreno (1994), "Capital Flows and Monetary Policy in East Asia", Centre for Pacific Basin Monetary and Economic Studies, Federal Reserve Bank of San Francisco, Working Paper 94-08.

Ghosh, S.K. (1991), Econometrics: Theory and Applications, Prentice Hall, Englewood Cliffs NJ.

Hung, W.S. and S.P. Tong (1996), "Financial Integration of the East Asian Economies: Evidence from the Saving-Investment Correlation", Hong Kong Economic Papers, 0(24), 101-111. 
Kaminsky, G.L. and S.L. Schmukler (1999), "What Triggers Market Jitters? A Chronicle of the Asian Crisis", Journal of International Money and Finance, 18, 537560 .

MacKinnnon, J.G. (1994), “Approximate Asymptotic Distribution Functions for Unit Root and Cointegration Tests", Journal of Business and Economic Statistics, 12, 167 176.

Mahieu and Schotman (1994), "Neglected Common Factors in Exchange Rate Volatility", Journal of Empirical Finance, 1, 279-311.

Masson, P.R. (1999), "Multiple Equilibria, Contagion, and the Emerging Market Crisis”, International Monetary Fund Working Paper No. 164.

Rummel, R.J. (1970), Applied Factor Analysis, Northwestern University Press, Evanston.

Stata (1999), Reference Manual, Stata Press, College Station, Texas.

Tse, Y.K. and L.K. Ng (1997), "The Cointegration of Asian Currencies Revisited", Japan and the World Economy, 9(1), 109-114.

Woo, W.T. and K. Hirayama (1995), "Monetary Autonomy in the Presence of Capital Flows: And Never the Twain Shall Meet, Except in East Asia", UC Davis, Department of Economics Working Paper, 95/17. 